\title{
Atomic-scale Structure of Ferric 0xyhydroxide Formed from Fe-Si Alloy in Aqueous Solutions Containing Different Salts
}

\author{
Sang-Koo KWON, ${ }^{1)}$ Katsuya INOUE, ${ }^{1)}$ Shigeru SUZUKI, ${ }^{1)}$ Masatoshi SAITO ${ }^{21}$ and Yoshio WASEDA ${ }^{1)}$ \\ 1) Institute of Multidisciplinary Research for Advanced Materials, Tohoku University, 2-1-1 Katahira, Aoba-ku, Sendai $980-8577$ \\ Japan. E-mail: ssuzuki@tagen.tohoku.ac.jp $\quad$ 2) School of Health Sciences, Faculty of Medicine, Niigata University, \\ Niigata, Niigata 951-8518, Japan.
}

(Received on February 13, 2006; accepted on June 5, 2006)

\begin{abstract}
Quantitative X-ray structural analysis coupled with reverse Monte Carlo (RMC) simulation was performed for characterizing the atomic-scale structure of $\gamma$-FeOOH (lepidocrocite) particles. These particles were formed by dipping pure iron or $\mathrm{Fe}-2$ mass \% Si alloy into aqueous solutions containing $\mathrm{Na}_{2} \mathrm{SO}_{4}$ or $\mathrm{NaCl}$. The realistic atomic-scale structures of $\gamma$ - FeOOH particles were estimated by fitting ordinary interference functions through the $\mathrm{RMC}$ simulation technique. The results revealed that the fundamental $\mathrm{FeO}_{6}$ octahedral structural units and their linkages were distorted in the $\gamma$-FeOOH particles formed from the Fe-Si alloy. This distortion was considered to be caused by the incorporation of silicate species into these particles. Transmission electron microscopy and Fourier-transform infrared (FT-IR) spectroscopy were employed for observing the morphology of the particles and for characterizing their bonding structure, respectively. Further, the amount of $\gamma$-FeOOH particles formed was measured in order to investigate their formation processes. The changes in the $\mathrm{pH}$ and oxidation-reduction potential (ORP) of the solutions were monitored during the formation of $\gamma$-FeOOH particles. Inductively coupled plasma analyses were also performed for determining the amounts of iron and silicon in supernatant solutions. The results indicated that the formation process of $\gamma$ $\mathrm{FeOOH}$ particles in the solutions was influenced by the addition of silicon to iron.
\end{abstract}

KEY WORDS: ferric oxyhydroxide; lepidocrocite; X-ray diffraction; atomic-scale structure.

\section{Introduction}

Atmospheric corrosion of iron-based alloys and steel is triggered by exposure to humid air, and corrosion products are formed on their substrates by various anodic and cathodic reactions that occur under various environments. ${ }^{1)}$ The species and fractions of the constituents of corrosion products are governed by $\mathrm{pH}$, oxidation rate, light, temperature, concentration of ferrous and ferric ions, foreign elements in the system, and so on. ${ }^{2)}$ In general, the actual corrosion process begins with the formation of ferrous ions through the oxidation of iron in aqueous solutions. The resulting corrosion products mainly comprise ferric ions and foreign cations and anions from alloying elements and the atmosphere. ${ }^{1,2)}$ The corrosion processes of steel are influenced by a layer of corrosion products formed on its surface. Typically, a protective layer formed on the surface of weathering steel reduces the corrosion rate. ${ }^{3-9)}$ Therefore, the atomic-scale structure and morphology of corrosion products are very important for understanding the corrosion mechanism. This is because they are closely related to the corrosion process on the surface of iron-based alloys and steel.

Ferric oxyhydroxides are one of the most important corrosion products, and $\gamma-\mathrm{FeOOH}$ is known to be a representative ferric oxyhydroxide formed on iron-based alloys and steel during atmospheric corrosion. These oxyhydroxides are formed by dissolution and recrystallization through the olation and oxolation of $\mathrm{FeO}_{6}$ octahedral units ${ }^{1,10,11)}$ that are maintained even during the amorphous state in the corrosion process. ${ }^{12)}$ The atomic-scale structures of ferric oxyhydroxides are fundamentally described based on the linkages of $\mathrm{FeO}_{6}$ octahedral units; these units are linked by corners, edges, faces, or combinations of these linkages to form different structural arrays. ${ }^{1,2,12)}$ The linkages of the local structure are influenced by cations and anions during the formation of ferric oxyhydroxides. It is possible that the atomicscale structures of ferric oxyhydroxides are correlated with their morphology and stability. ${ }^{13,14)}$ It is reported that some elements strongly affect the formation and atomic-scale structures of ferric oxyhydroxides. ${ }^{15-23)}$ Therefore, the influence of cations and anions on the atomic-scale structures of ferric oxyhydroxides formed by iron-based alloys and steel under various environments are strongly required in order to understand the relation between the atomic-scale structures and corrosion process.

Recently, quantitative X-ray structural analysis using ordinary and anomalous X-ray scattering (AXS) coupled with reverse Monte Carlo (RMC) simulation, which was verified in various states such as liquids, glasses, and aperiodic systems, ${ }^{24-27)}$ was successfully performed for the characterization of the atomic-scale structures of ferric oxyhydrox- 
ides. $^{13-15,21,22)}$ However, the anions in corrosion products such as carbonates, silicates, and sulfates are composed of relatively light elements that cannot be easily identified by X-ray scattering. Thus, the application of the AXS measurement with synchrotron radiations is limited to some extent. In this regard, quantitative X-ray structural analysis coupled with RMC simulation using in-house equipment and other spectroscopic methods is significantly more effective for investigating the influence of anions on the atomic-scale structure of corrosion products; this is proved in our previous reports. ${ }^{15)}$

Silicon is one of the most important elements of steel and is often used as an alloying element in order to improve corrosion resistance. ${ }^{28-30)}$ It is known that during atmospheric corrosion, silicate ions are formed by the oxidation of silicon present in steel. ${ }^{31,32)}$ However, the influence of silicon in iron-based alloys and steel on the formation and atomic-scale structures of ferric oxyhydroxides during the actual corrosion process has not yet been clarified. Actually, the corrosion products, which are formed through the repetition of wetting and drying processes during atmospheric corrosion, are complicated and somewhat different from the corrosion products formed in aqueous solutions. However, the atomic-scale structural characterization of ferric oxyhydroxides formed in aqueous solutions is very effective to investigate an influence of silicon on the structure of specific corrosion products without other factors in the atmospheric corrosion. Such an initial layer of ferric oxyhydroxides formed on the surface of steel may also affect subsequent corrosion process. With this background, we studied the atomic-scale structures of ferric oxyhydroxides formed from $\mathrm{Fe}-\mathrm{Si}$ alloy in aqueous solutions. In this study, quantitative X-ray structural analysis using in-house X-ray diffraction equipment with $\mathrm{Mo} \mathrm{K} \alpha$ radiation coupled with RMC simulation was used for investigating the atomicscale structure of $\gamma$-FeOOH particles. These particles were formed from $\mathrm{Fe}-\mathrm{Si}$ alloy substrates by reaction with solutions of 2 mass $\% \mathrm{Na}_{2} \mathrm{SO}_{4}$ and $\mathrm{NaCl}$. The morphologies of these particles were observed by transmission electron microscopy, and the changes in their bonding structure were analyzed by infrared spectroscopy. Furthermore, in order to characterize the reaction field of nucleation and growth of the solid particles of $\gamma$-FeOOH in the solutions, the solutions were analyzed using different methods. The changes in the $\mathrm{pH}$ and oxidation-reduction potential (ORP) of the solutions were monitored during the reaction. The amount of $\gamma$-FeOOH particles formed was measured, and inductively coupled plasma atomic emission spectrometry (ICPAES) analyses were performed in order to investigate the changes in the content ratio of silicon to iron dissolved in supernatant solutions.

\section{Experimental}

\subsection{Sample Preparation}

Ingots of pure iron $(99.99 \%)$ and $\mathrm{Fe}-2 \mathrm{mass} \% \mathrm{Si}$ alloy were produced by vacuum induction melting of electrolytic iron and pure silicon. They were rolled and shaped into samples with dimensions of $30 \mathrm{~mm} \times 25 \mathrm{~mm} \times 1 \mathrm{~mm}$. They were then dipped into $20 \mathrm{~mL}$ aqueous solutions of 2 mass $\%$ $\mathrm{Na}_{2} \mathrm{SO}_{4}$ and $\mathrm{NaCl}$ in open $100 \mathrm{~mL}$ glass bottles up to $14 \mathrm{~d}$ at room temperature. Colloidal particles, which primarily comprised $\gamma$-FeOOH, were filtered through a $0.2 \mu \mathrm{m}$ membrane filter in order to separate solid particles from the supernatant solutions of the suspensions. The solid particles were washed with distilled water and dried for $48 \mathrm{~h}$ at room temperature in air. Hereafter, $\gamma$-FeOOH particles formed from pure iron and the $\mathrm{Fe}-\mathrm{Si}$ alloy in the solution of 2 mass $\% \mathrm{Na}_{2} \mathrm{SO}_{4}$ are referred to as $\gamma-\mathrm{Fe} / \mathrm{Na}_{2} \mathrm{SO}_{4}$ and $\gamma-$ $\mathrm{Fe}-\mathrm{Si} / \mathrm{Na}_{2} \mathrm{SO}_{4}$, respectively. $\gamma-\mathrm{FeOOH}$ particles formed from pure iron and the $\mathrm{Fe}-\mathrm{Si}$ alloy in the solution of 2 mass $\% \mathrm{NaCl}$ are referred to as $\gamma-\mathrm{Fe} / \mathrm{NaCl}$ and $\gamma$ $\mathrm{Fe}-\mathrm{Si} / \mathrm{NaCl}$, respectively.

\subsection{Characterizations}

X-ray diffraction measurements were performed using in-house X-ray diffraction equipment with Mo $\mathrm{K} \alpha$ radiation of $17.447 \mathrm{keV}(50 \mathrm{kV}, 30 \mathrm{~mA})$, Rigaku RINT-2200. The scattering X-ray intensity was measured in a wide range of wave vectors in order to determine accurate interference functions of the samples. The realistic atomic-scale structures of $\gamma$-FeOOH particles were determined by fitting the experimental interference functions with those calculated using statistical optimization; in this optimization, the atomic positions were changed from the initial configurations in an ideal structure by the RMC simulation technique. ${ }^{13-15,24-27)}$ In this simulation, the supercells of $\gamma$ $\mathrm{FeOOH}$ were determined with dimensions of $3.756 \mathrm{~nm} \times$ $3.870 \mathrm{~nm} \times 3.684 \mathrm{~nm}$ in order to ensure that the crystal was composed of a sufficient number of atoms for computational accuracy. The simulation was accomplished with initial configurations of 4320 atoms (1 440 for iron and 2880 for oxygen) positioned in the supercell of $\gamma$-FeOOH. The atomic-scale structures were described using $\mathrm{FeO}_{6}$ octahedral units and their linkages in $\gamma-\mathrm{FeOOH}$ particles by using partial distribution functions. The typical periodic boundary conditions, in which the cell is surrounded by its images, were applied and the interference functions were calculated to obtain the quantitative structural information related to nearest-neighbor correlations. Detailed methods of these measurements and characterizations are described elsewhere. $^{24)}$

A transmission electron microscope, JEOL JEM-1200EX II, was used for observing the microscopic morphology of the solid particles. A Fourier-transform infrared spectroscope (FT-IR), DIGILAB FTS 7000, was used for characterizing the influence of silicon on the bonding structure of $\gamma$-FeOOH particles formed in the solutions. The amount of solid particles, particularly those of $\gamma-\mathrm{FeOOH}$, formed at different times was weighted. The changes in the $\mathrm{pH}$ and ORP of the suspensions with reaction time were monitored using a TOA DKK IM-55G ion meter. A platinum electrode, which was referred to $\mathrm{Ag} / \mathrm{AgCl}$ in $3.33 \mathrm{~mol} / \mathrm{dm}^{-3}$ $\mathrm{KCl}$ solution, was used for ORP measurement. The contents of iron and silicon in the separated supernatant solutions were analyzed using ICP-AES equipment, PerkinElmer Optima 3300. 


\section{Results and Discussion}

\subsection{Atomic-scale Arrangements of Different $\gamma$ - FeOOH Particles}

Figures 1(a)-1(d) show the X-ray diffraction patterns as a function of $2 \theta$ for $\gamma-\mathrm{Fe} / \mathrm{Na}_{2} \mathrm{SO}_{4}, \gamma-\mathrm{Fe}-\mathrm{Si} / \mathrm{Na}_{2} \mathrm{SO}_{4}, \gamma-$ $\mathrm{Fe} / \mathrm{NaCl}$, and $\gamma-\mathrm{Fe}-\mathrm{Si} / \mathrm{NaCl}$, respectively; these particles were obtained by the reaction in the solutions of 2 mass $\%$ $\mathrm{Na}_{2} \mathrm{SO}_{4}$ and $\mathrm{NaCl}$. The reference lines for $\gamma-\mathrm{FeOOH}$ mentioned in the JCPDS database are also shown in Fig. 1. The fundamental structure of these samples was identical to that of $\gamma$-FeOOH indicated by the reference lines, and the other phases were not observed in all X-ray diffraction patterns. However, the diffraction patterns revealed that the intensity ratios of the diffraction peaks of $\gamma-\mathrm{Fe}-\mathrm{Si} / \mathrm{Na}_{2} \mathrm{SO}_{4}$ and $\gamma$ $\mathrm{Fe}-\mathrm{Si} / \mathrm{NaCl}$ differed from those of $\gamma-\mathrm{Fe} / \mathrm{Na}_{2} \mathrm{SO}_{4}$ and $\gamma-$ $\mathrm{Fe} / \mathrm{NaCl}$. These results indicate that the short-range and/or middle-range structures in $\gamma$-Fe- $\mathrm{Si} / \mathrm{Na}_{2} \mathrm{SO}_{4}$ and $\gamma$-Fe$\mathrm{Si} / \mathrm{NaCl}$ were changed; this may be attributed to the effect of silicon during the formation of $\gamma$-FeOOH particles.

The experimental and calculated interference functions $Q i(Q)$ for $\gamma-\mathrm{Fe} / \mathrm{Na}_{2} \mathrm{SO}_{4}, \gamma-\mathrm{Fe}-\mathrm{Si} / \mathrm{Na}_{2} \mathrm{SO}_{4}, \gamma-\mathrm{Fe} / \mathrm{NaCl}$, and $\gamma-\mathrm{Fe}-\mathrm{Si} / \mathrm{NaCl}$ are shown in Figs. 2(a)-2(d), respectively. The experimental ordinary interference functions obtained from the X-ray diffraction patterns are shown as dots. The realistic atomic-scale arrangements of $\gamma$-Fe/ $\mathrm{Na}_{2} \mathrm{SO}_{4}, \quad \gamma$ $\mathrm{Fe}-\mathrm{Si} / \mathrm{Na}_{2} \mathrm{SO}_{4}, \gamma-\mathrm{Fe} / \mathrm{NaCl}$, and $\gamma-\mathrm{Fe}-\mathrm{Si} / \mathrm{NaCl}$ were determined by fitting the interference functions computed by the RMC method, which are shown as solid lines in Fig. 2, with the experimental interference functions. New atomic configurations in the supercell were generated by randomly changing the atomic positions for structural optimization in the crystal. The interference functions were calculated by accepting or rejecting these configurations based on a comparison with previous configuration data. When the difference between the experimental and calculated values was less than that in the previous configuration, the new configuration was accepted; otherwise, it was rejected. This iterative process was accomplished with sufficient time until a reasonable convergence was obtained by statistical optimization. In all cases, the computed interference functions were in good agreement with the experimental results, although some deviations from the experimental data occurred possibly due to the relatively simple assumptions of this RMC simulation. For the calculation, the contribution of silicon in X-ray scattering was assumed to be negligible because its atomic position in the unit cell could not be identified and it could not be easily detected by X-ray scattering since it is a relatively light element. However, the atomic-scale structures determined by the RMC simulation in this study were considered to be quite reasonable because they were calculated from precise measurements.

Figures 3(a)-3(c) show the partial pair distribution functions of the pairs of $\mathrm{Fe}-\mathrm{O}, \mathrm{Fe}-\mathrm{Fe}$, and $\mathrm{O}-\mathrm{O}$ in $\gamma-\mathrm{Fe} / \mathrm{Na}_{2} \mathrm{SO}_{4}$ and $\gamma-\mathrm{Fe}-\mathrm{Si} / \mathrm{Na}_{2} \mathrm{SO}_{4}$. These functions were calculated from the new atomic configurations by statistical optimization between the experimental and calculated interference functions through the RMC simulation technique. The partial pair distribution functions of the pairs of $\mathrm{Fe}-\mathrm{O}, \mathrm{Fe}-\mathrm{Fe}$, and $\mathrm{O}-\mathrm{O}$ in $\gamma-\mathrm{Fe} / \mathrm{NaCl}$ and $\gamma-\mathrm{Fe}-\mathrm{Si} / \mathrm{NaCl}$ are shown in Figs. 4(a)-4(c). These functions suggest that the structures of $\gamma$ -

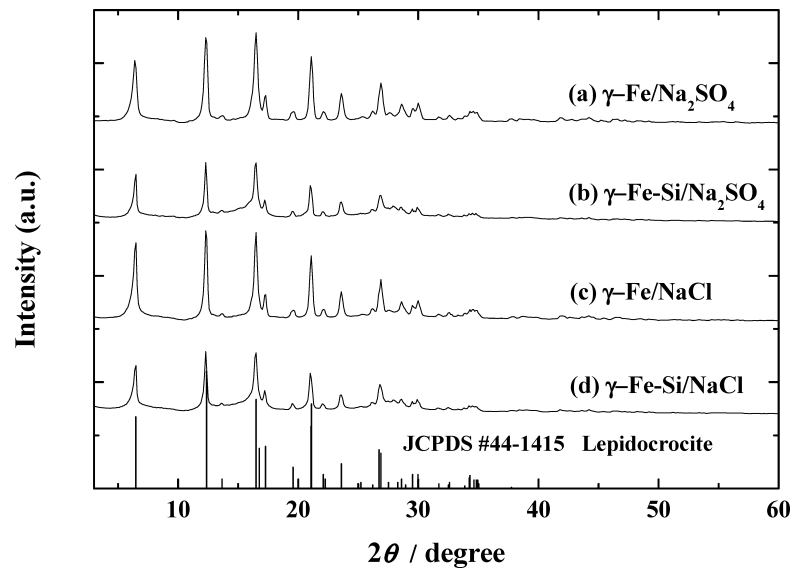

Fig. 1. X-ray diffraction patterns as a function of $2 \theta$ for (a) $\gamma$ $\mathrm{Fe} / \mathrm{Na}_{2} \mathrm{SO}_{4}$, (b) $\gamma-\mathrm{Fe}-\mathrm{Si} / \mathrm{Na}_{2} \mathrm{SO}_{4}$, (c) $\gamma-\mathrm{Fe} / \mathrm{NaCl}$, and (d) $\gamma-\mathrm{Fe}-\mathrm{Si} / \mathrm{NaCl}$. These particles were obtained by the reaction in the solutions of 2 mass $\% \mathrm{Na}_{2} \mathrm{SO}_{4}$ and $\mathrm{NaCl}$ using in-house $\mathrm{X}$-ray diffraction equipment with $\mathrm{Mo} \mathrm{K} \alpha$ radiation of $17.447 \mathrm{keV}$. The reference lines for $\gamma-\mathrm{FeOOH}$ mentioned in the JCPDS database are also shown.

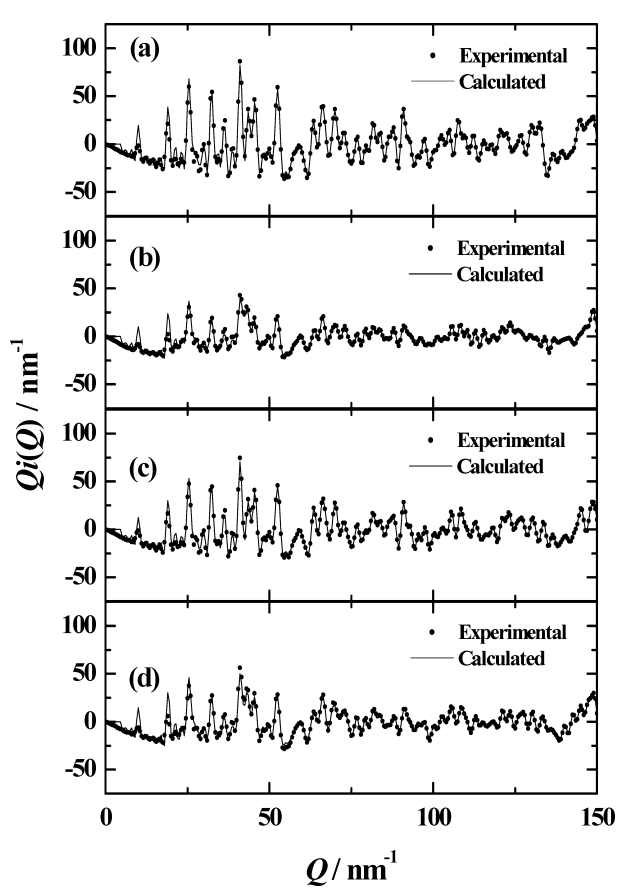

Fig. 2. Experimental and calculated interference functions $Q i(Q)$ estimated by the RMC simulation for (a) $\gamma-\mathrm{Fe} / \mathrm{Na}_{2} \mathrm{SO}_{4}$, (b) $\gamma-\mathrm{Fe}-\mathrm{Si} / \mathrm{Na}_{2} \mathrm{SO}_{4}$, (c) $\gamma-\mathrm{Fe} / \mathrm{NaCl}$, and (d) $\gamma-\mathrm{Fe}-$ $\mathrm{Si} / \mathrm{NaCl}$. Dots and solid lines indicate experimental and calculated values, respectively.

$\mathrm{FeOOH}$ particles depend on the presence of silicon in iron instead of the species of the salts in the solutions. Some deviations are observed in the peaks of the partial pair distribution functions of $\mathrm{Fe}-\mathrm{O}, g_{\mathrm{Fe}-\mathrm{O}}$, that are located around $0.2 \mathrm{~nm}$, between $\gamma-\mathrm{Fe}-\mathrm{Si} / \mathrm{Na}_{2} \mathrm{SO}_{4}$ and $\gamma-\mathrm{Fe}-\mathrm{Si} / \mathrm{NaCl}$. Moreover, the distribution profiles of $\gamma-\mathrm{Fe}-\mathrm{Si} / \mathrm{Na}_{2} \mathrm{SO}_{4}$ and $\gamma$ $\mathrm{Fe}-\mathrm{Si} / \mathrm{NaCl}$ are broader than those of $\gamma-\mathrm{Fe} / \mathrm{Na}_{2} \mathrm{SO}_{4}$ and $\gamma$ $\mathrm{Fe} / \mathrm{NaCl}$. This indicates that the fundamental $\mathrm{FeO}_{6}$ octahedral units are distorted and the iron-oxygen neighboring correlations in $\gamma-\mathrm{Fe}-\mathrm{Si} / \mathrm{Na}_{2} \mathrm{SO}_{4}$ and $\gamma-\mathrm{Fe}-\mathrm{Si} / \mathrm{NaCl}$ are distributed, possibly by the influence of silicate ions. The pair distribution functions of $\mathrm{Fe}-\mathrm{Fe}, g_{\mathrm{Fe}-\mathrm{Fe}}$, for $\gamma$-Fe- $\mathrm{Si} / \mathrm{Na}_{2} \mathrm{SO}_{4}$ 


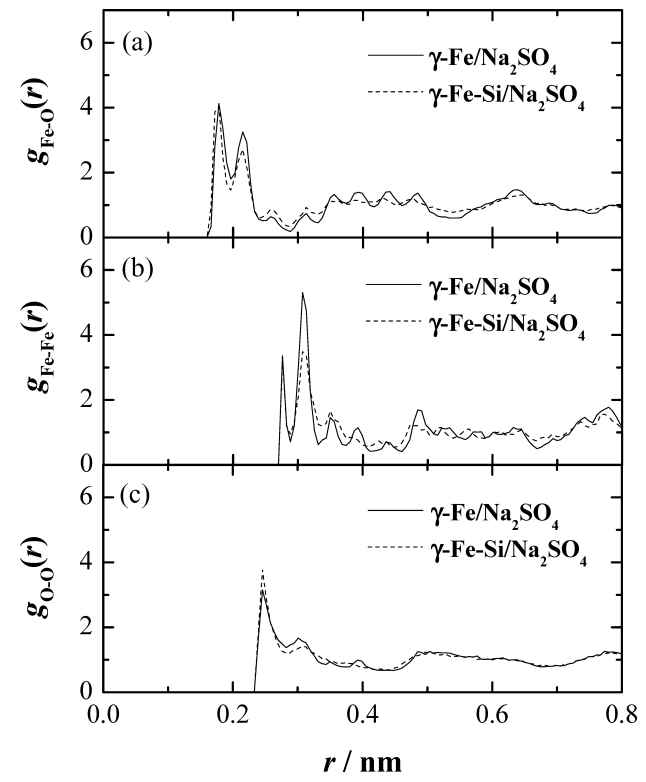

Fig. 3. Partial pair distribution functions of the pairs of (a) $\mathrm{Fe}-\mathrm{O}$, (b) $\mathrm{Fe}-\mathrm{Fe}$, and (c) $\mathrm{O}-\mathrm{O}$ estimated by the $\mathrm{RMC}$ simulation for $\gamma-\mathrm{Fe} / \mathrm{Na}_{2} \mathrm{SO}_{4}$ and $\gamma-\mathrm{Fe}-\mathrm{Si} / \mathrm{Na}_{2} \mathrm{SO}_{4}$ obtained by the reaction for $14 \mathrm{~d}$ in the solution of 2 mass $\% \mathrm{Na}_{2} \mathrm{SO}_{4}$.

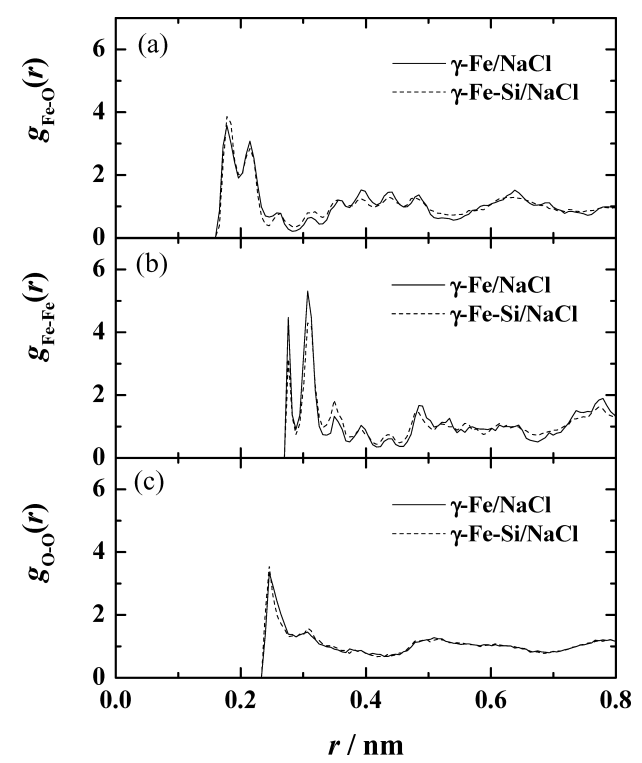

Fig. 4. Partial pair distribution functions of the pairs of (a) $\mathrm{Fe}-\mathrm{O}$, (b) $\mathrm{Fe}-\mathrm{Fe}$, and (c) $\mathrm{O}-\mathrm{O}$ estimated by the RMC simulation for $\gamma-\mathrm{Fe} / \mathrm{NaCl}$ and $\gamma-\mathrm{Fe}-\mathrm{Si} / \mathrm{NaCl}$ obtained by the reaction for $14 \mathrm{~d}$ in the solution of 2 mass $\% \mathrm{NaCl}$.

and $\gamma-\mathrm{Fe}-\mathrm{Si} / \mathrm{NaCl}$ differ significantly from those of $\gamma$ $\mathrm{Fe} / \mathrm{Na}_{2} \mathrm{SO}_{4}$ and $\gamma-\mathrm{Fe} / \mathrm{NaCl}$, as shown in Figs. 3(b) and 4(b). The peaks of $g_{\mathrm{Fe}-\mathrm{Fe}}$ for $\gamma$-Fe-Si $/ \mathrm{Na}_{2} \mathrm{SO}_{4}$ and $\gamma$ - $\mathrm{Fe}-\mathrm{Si} / \mathrm{NaCl}$ are broader than those for $\gamma-\mathrm{Fe} / \mathrm{Na}_{2} \mathrm{SO}_{4}$ and $\gamma-\mathrm{Fe} / \mathrm{NaCl}$. Some differences are also observed in the pair distribution functions of $\mathrm{O}-\mathrm{O}, g_{\mathrm{O}-\mathrm{O}}$, between $\gamma-\mathrm{Fe} / \mathrm{Na}_{2} \mathrm{SO}_{4}$ and $\gamma$ $\mathrm{Fe}-\mathrm{Si} / \mathrm{Na}_{2} \mathrm{SO}_{4}$ and between $\gamma-\mathrm{Fe} / \mathrm{NaCl}$ and $\gamma-\mathrm{Fe}-\mathrm{Si} / \mathrm{NaCl}$. Therefore, these distribution profiles clearly indicate that the distance of the fundamental $\mathrm{FeO}_{6}$ octahedral units and their linkages related to the middle-range order in the crystal are distorted by the incorporation of silicate ions during the formation process of $\gamma$ - $\mathrm{FeOOH}$ particles in the solutions of $\mathrm{Na}_{2} \mathrm{SO}_{4}$ and $\mathrm{NaCl}$.

Figures 5(a)-5(d) show the realistic atomic arrange-
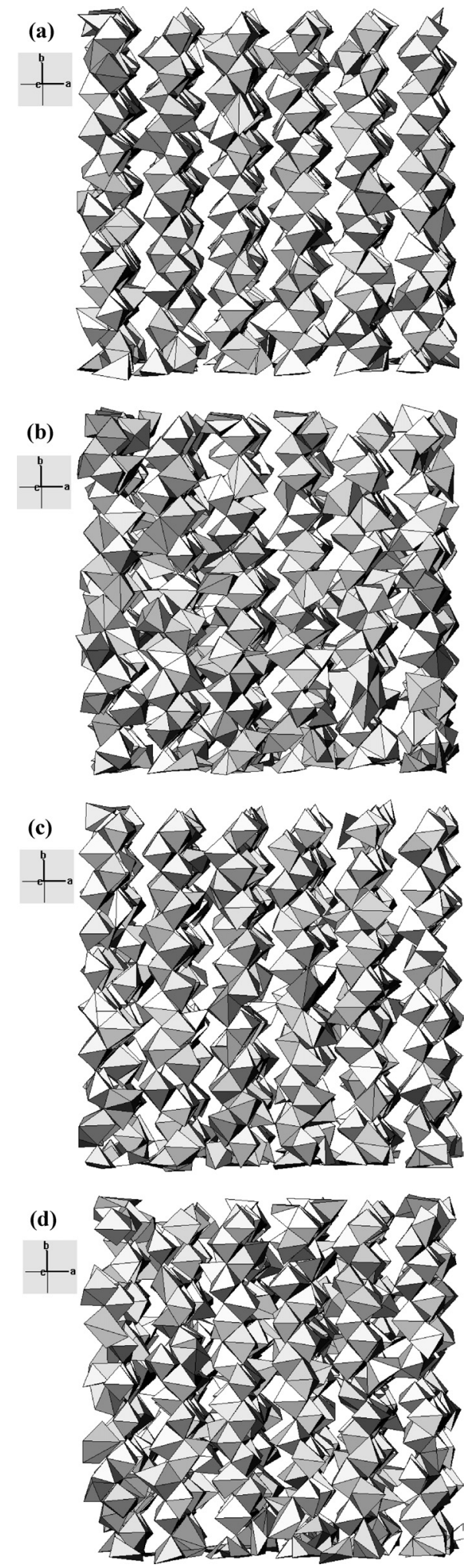

Fig. 5. Atomic arrangements of (a) $\gamma-\mathrm{Fe} / \mathrm{Na}_{2} \mathrm{SO}_{4}$, (b) $\gamma$ $\mathrm{Fe}-\mathrm{Si} / \mathrm{Na}_{2} \mathrm{SO}_{4}$, (c) $\gamma-\mathrm{Fe} / \mathrm{NaCl}$, and (d) $\gamma-\mathrm{Fe}-\mathrm{Si} / \mathrm{NaCl}$ determined by the RMC simulation. The arrangements are described using $\mathrm{FeO}_{6}$ octahedral structural units.

ments in the crystal estimated by the RMC simulation for $\gamma$-Fe/ $\mathrm{Na}_{2} \mathrm{SO}_{4}, \quad \gamma$-Fe-Si/ $\mathrm{Na}_{2} \mathrm{SO}_{4}, \quad \gamma-\mathrm{Fe} / \mathrm{NaCl}, \quad$ and $\quad \gamma-\mathrm{Fe}-$ $\mathrm{Si} / \mathrm{NaCl}$, respectively. $\gamma$-FeOOH exhibits a layered structure in which four formula units exist in an orthorhombic unit cell. The anions are stacked in cubic close-packing arrays, and Fe ions occupy the octahedral interstices. The fun- 
damental structures can be described using $\mathrm{FeO}_{6}$ octahedral units. The structure of $\gamma$-FeOOH comprises double chains of edge-sharing $\mathrm{FeO}_{6}$ octahedral units. These double chains share edges with adjacent double chains to form corrugated sheets of $\mathrm{FeO}_{6}$ octahedral units; they are linked only by hydrogen bonds, which have not been shown. The atomic arrangements of $\gamma-\mathrm{Fe} / \mathrm{Na}_{2} \mathrm{SO}_{4}$ and $\gamma-\mathrm{Fe} / \mathrm{NaCl}$ indicate that the linkages of $\mathrm{FeO}_{6}$ octahedral structure units are similar to those of the ideal $\gamma$-FeOOH structure, although some structural distortion in the linkages of $\mathrm{FeO}_{6}$ occurs due to the incorporation of unwanted anions during the formation of $\gamma$-FeOOH particles. On the other hand, the fundamental $\mathrm{FeO}_{6}$ octahedral units in $\gamma$-Fe- $\mathrm{Si} / \mathrm{Na}_{2} \mathrm{SO}_{4}$ and $\gamma$ - $\mathrm{Fe}-\mathrm{Si} / \mathrm{NaCl}$ are distorted and their linkages deviate from those of $\gamma$ $\mathrm{Fe} / \mathrm{Na}_{2} \mathrm{SO}_{4}$ and $\gamma-\mathrm{Fe} / \mathrm{NaCl}$. Thus, it is likely that the resulting atomic-scale structures are influenced by the incorporation of silicate species in the formation process of $\gamma$ $\mathrm{FeOOH}$ particles. In real corrosion processes, foreign species such as cations and anions dissolved in the solutions may influence not only the local structure but also morphology of the corrosion products by the incorporation in the corrosion products. Thus, such distorted atomic-scale structure of corrosion products may result in the formation of a relatively dense rust layer on the surface of iron-based alloys, which is believed to tend to suppress the diffusion or permeation of oxygen, other foreign species through the rust layer, ${ }^{14)}$ although further experiments are required for verify such a mechanism. Furthermore, the present method for estimating the atomic-scale arrangements is considered to be useful for discussing the formation processes of corrosion products and for understanding the corrosion mechanism in various aqueous solutions that contain foreign species.

\subsection{Transmission Electron Microscopy and Infrared Spectroscopy}

The transmission electron micrographs of $\gamma-\mathrm{Fe} / \mathrm{Na}_{2} \mathrm{SO}_{4}$, $\gamma-\mathrm{Fe}-\mathrm{Si} / \mathrm{Na}_{2} \mathrm{SO}_{4}, \gamma-\mathrm{Fe} / \mathrm{NaCl}$, and $\gamma-\mathrm{Fe}-\mathrm{Si} / \mathrm{NaCl}$ produced by the reaction for $14 \mathrm{~d}$ are shown in Figs. 6(a)-6(d), respectively. The solid particles of $\gamma-\mathrm{Fe} / \mathrm{Na}_{2} \mathrm{SO}_{4}$ and $\gamma$ $\mathrm{Fe} / \mathrm{NaCl}$ exhibited plate-like morphologies. On the other hand, the particle sizes of $\gamma-\mathrm{Fe}-\mathrm{Si} / \mathrm{Na}_{2} \mathrm{SO}_{4}$ and $\gamma$ $\mathrm{Fe}-\mathrm{Si} / \mathrm{NaCl}$ decreased slightly and the aspect ratio of solid particles was greater than that of $\gamma-\mathrm{Fe} / \mathrm{Na}_{2} \mathrm{SO}_{4}$ and $\gamma$ $\mathrm{Fe} / \mathrm{NaCl}$. Electron probe microanalysis revealed that the molar ratios of silicon to iron in $\gamma-\mathrm{Fe}-\mathrm{Si} / \mathrm{Na}_{2} \mathrm{SO}_{4}$ and $\gamma$ $\mathrm{Fe}-\mathrm{Si} / \mathrm{NaCl}$ were 0.037 and 0.043 , respectively. Therefore, the morphological changes of $\gamma-\mathrm{Fe}-\mathrm{Si} / \mathrm{Na}_{2} \mathrm{SO}_{4}$ and $\gamma$ $\mathrm{Fe}-\mathrm{Si} / \mathrm{NaCl}$ were attributed to the incorporation of silicate species during the formation of $\gamma$-FeOOH particles in the solutions of 2 mass $\% \mathrm{Na}_{2} \mathrm{SO}_{4}$ and $\mathrm{NaCl}$.

Figures 7(a)-7(d) show the FT-IR absorption spectra in the range of $500-1500 \mathrm{~cm}^{-1}$ for $\gamma-\mathrm{Fe} / \mathrm{Na}_{2} \mathrm{SO}_{4}, \gamma$ $\mathrm{Fe}-\mathrm{Si} / \mathrm{Na}_{2} \mathrm{SO}_{4}, \gamma-\mathrm{Fe} / \mathrm{NaCl}$, and $\gamma-\mathrm{Fe}-\mathrm{Si} / \mathrm{NaCl}$, respectively. For these samples, three main absorption peaks were observed around 1150,1020 , and $750 \mathrm{~cm}^{-1}$, which were similar to those of pure $\gamma$-FeOOH particles. ${ }^{33-35)}$ The absorption bands of $\gamma-\mathrm{Fe}-\mathrm{Si} / \mathrm{Na}_{2} \mathrm{SO}_{4}$ and $\gamma-\mathrm{Fe}-\mathrm{Si} / \mathrm{NaCl}$ decreased and broadened; this may be due to poor crystallinity. In the spectra of $\gamma-\mathrm{Fe}-\mathrm{Si} / \mathrm{Na}_{2} \mathrm{SO}_{4}$ and $\gamma-\mathrm{Fe}-\mathrm{Si} / \mathrm{NaCl}$, new absorption bands were observed around 900 and $700 \mathrm{~cm}^{-1}$. They
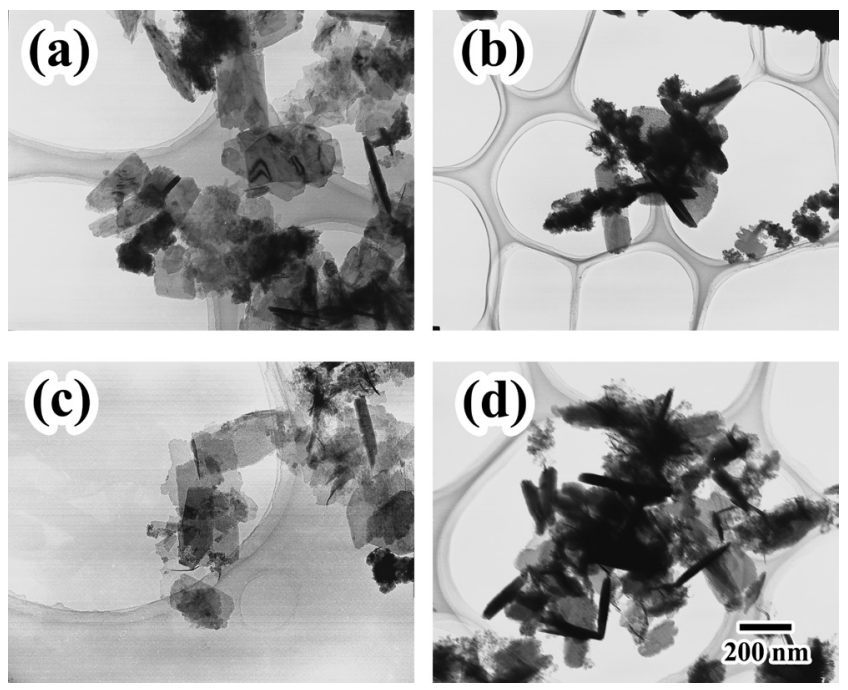

Fig. 6. Transmission electron micrographs of (a) $\gamma-\mathrm{Fe} / \mathrm{Na}_{2} \mathrm{SO}_{4}$, (b) $\gamma-\mathrm{Fe}-\mathrm{Si} / \mathrm{Na}_{2} \mathrm{SO}_{4}$, (c) $\gamma-\mathrm{Fe} / \mathrm{NaCl}$, and (d) $\gamma-\mathrm{Fe}-$ $\mathrm{Si} / \mathrm{NaCl}$.

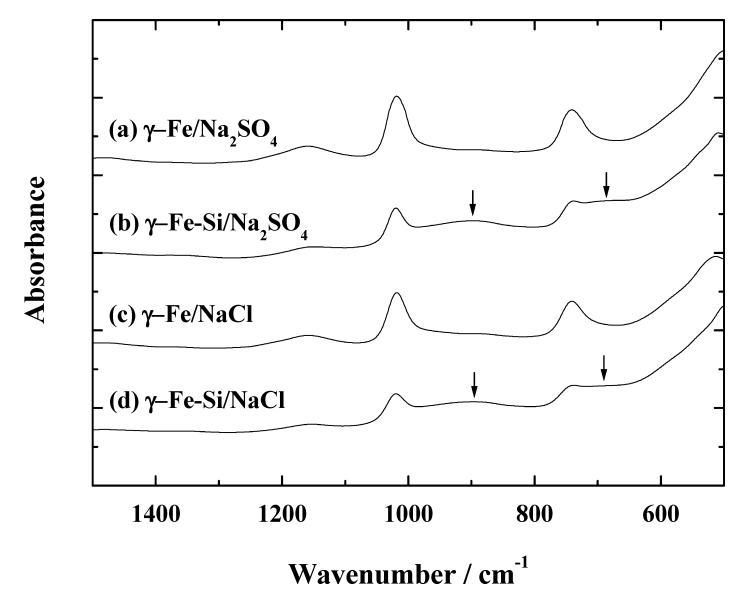

Fig. 7. FT-IR absorption spectra of $\gamma$-Fe/ $/ \mathrm{Na}_{2} \mathrm{SO}_{4}, \quad \gamma$-Fe$\mathrm{Si} / \mathrm{Na}_{2} \mathrm{SO}_{4}, \gamma-\mathrm{Fe} / \mathrm{NaCl}$, and $\gamma-\mathrm{Fe}-\mathrm{Si} / \mathrm{NaCl}$ obtained by the reaction in the solutions of 2 mass $\%$ (a) $\mathrm{Na}_{2} \mathrm{SO}_{4}$ and (b) $\mathrm{NaCl}$.

may be attributed to the $\mathrm{Fe}-\mathrm{O}-\mathrm{Si}$ linkage of the particles, which occurred due to the incorporation of silicate species during the formation of $\gamma$-FeOOH particles in the solutions of 2 mass $\% \mathrm{Na}_{2} \mathrm{SO}_{4}$ and $\mathrm{NaCl}^{23,32)}$ This result was in good agreement with our previous results of the influence of silicate ions on the conversion process of ferric hydroxide to $\beta$-FeOOH and $\alpha-\mathrm{Fe}_{2} \mathrm{O}_{3}{ }^{20,23)}$

\subsection{Formation of Particles and Changes of Aqueous Solutions}

Figure 8 shows the changes in the amount of solid particles formed at different reaction times in the solutions of 2 mass $\% \mathrm{Na}_{2} \mathrm{SO}_{4}$ and $\mathrm{NaCl}$. These results indicate that the formation rate of $\gamma$-FeOOH particles decreases in the $\mathrm{Fe}-\mathrm{Si}$ alloy irrespective of the type of solution. Thus, silicon in the alloy may affect the formation of $\gamma-\mathrm{FeOOH}$ particles in the solutions possibly by the formation of silicate ions, although a small amount of adhesive particles is formed on the surfaces of pure iron and the Fe-Si alloy. Therefore, it is considered that silicon dissolved in the solution influences the formation of corrosion products in the aqueous solu- 


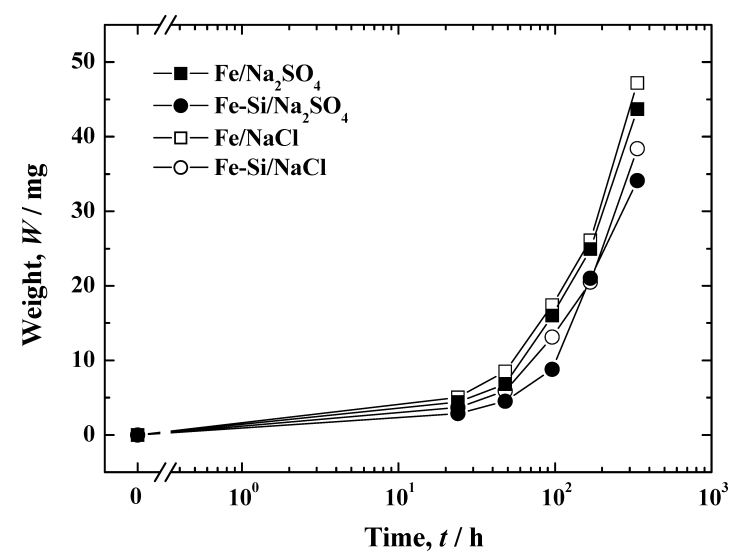

Fig. 8. Changes in the amount of solid particles formed at different reaction times by the reaction of pure iron and $\mathrm{Fe}-\mathrm{Si}$ alloy substrates with the solutions of $2 \mathrm{mass} \% \mathrm{Na}_{2} \mathrm{SO}_{4}$ and $\mathrm{NaCl}$.

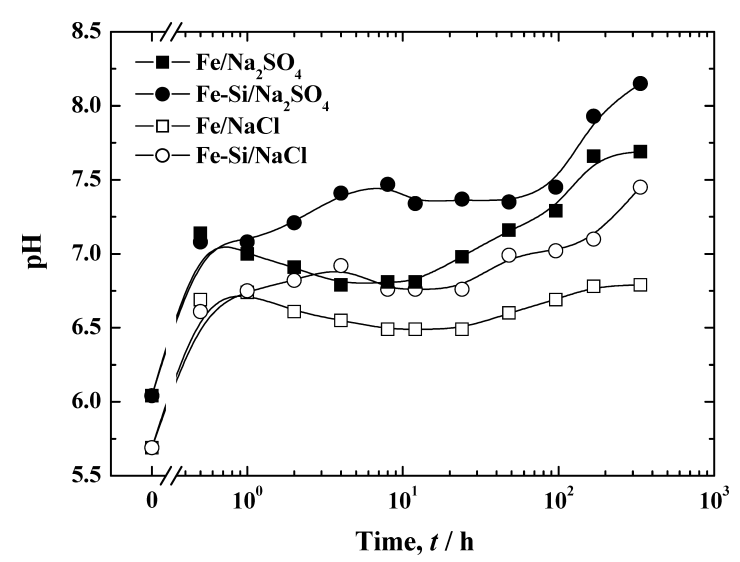

Fig. 9. Variations in $\mathrm{pH}$ as a function of reaction time. The variations were observed during the reaction of pure iron and $\mathrm{Fe}-\mathrm{Si}$ alloy substrates with the solutions of 2 mass $\%$ $\mathrm{Na}_{2} \mathrm{SO}_{4}$ and $\mathrm{NaCl}$.

tions.

Figure 9 shows the variation of $\mathrm{pH}$ during the reaction in the solutions of 2 mass $\% \mathrm{Na}_{2} \mathrm{SO}_{4}$ and $\mathrm{NaCl}$. In the case of pure iron, the $\mathrm{pH}$ increases in the initial stage and then decreases slightly. It appears to be stable from 4 to $12 \mathrm{~h}$ and increases thereafter. This tendency is similar between the solutions of 2 mass $\% \mathrm{Na}_{2} \mathrm{SO}_{4}$ and $\mathrm{NaCl}$. In the case of the $\mathrm{Fe}-\mathrm{Si}$ alloy, the $\mathrm{pH}$ increases in the initial stage; thereafter, it increases gradually in comparison with that in the case of pure iron. During the reaction, the $\mathrm{pH}$ level is maintained higher than that in the case of pure iron.

These reactions should be interpreted with the elemental reaction of the dissolution and precipitation of ferrous and ferric ions. $\gamma$-FeOOH particles in water are formed or precipitated from ferrous ions dissolved in it, according to the following reactions. ${ }^{1,2)}$

$$
\begin{aligned}
& \mathrm{Fe} \rightarrow \mathrm{Fe}^{2+}+2 \mathrm{e}^{-} \\
& 1 / 2 \mathrm{O}_{2}+\mathrm{H}_{2} \mathrm{O}+2 \mathrm{e}^{-} \rightarrow 2 \mathrm{OH}^{-} \\
& 2 \mathrm{Fe}^{2+}+3 \mathrm{H}_{2} \mathrm{O}+1 / 2 \mathrm{O}_{2} \rightarrow 2 \mathrm{FeOOH}+4 \mathrm{H}^{+}
\end{aligned}
$$

Metallic iron is dissolved in the solutions according to the anodic reaction given in Eq. (1), while the cathodic reaction

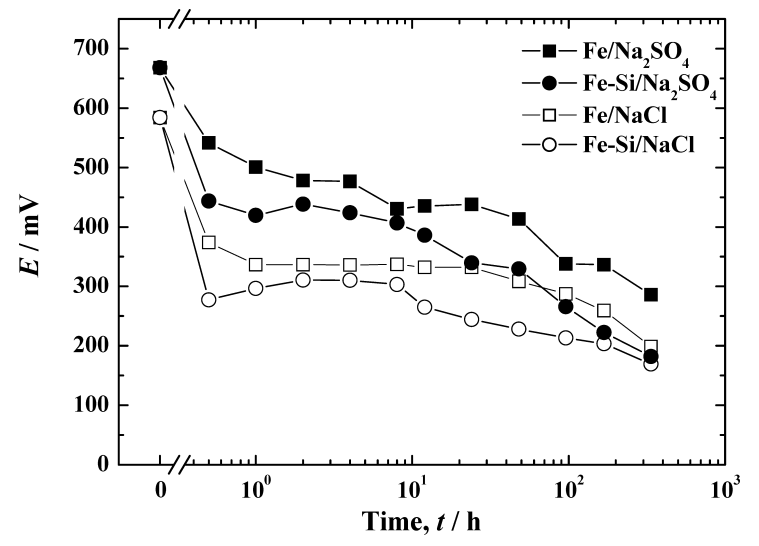

Fig. 10. Variations in ORP as a function of reaction time. The variations were observed during the reaction of pure iron and $\mathrm{Fe}-\mathrm{Si}$ alloy substrates with the solutions of 2 mass $\% \mathrm{Na}_{2} \mathrm{SO}_{4}$ and $\mathrm{NaCl}$.

given in Eq. (2) is balanced with the anodic reaction. Then, it is considered that the $\mathrm{pH}$ increases through the formation of $\mathrm{OH}^{-}$ions by the cathodic reaction. These reactions correspond to the increase in the $\mathrm{pH}$ observed in the initial stage, as shown in Fig. 9. When the content of ferrous or ferric ions increases in the aqueous solution and they react with oxygen, FeOOH particles may be precipitated according to Eq. (3). It should be noted that the reaction of Eq. (3) is simplified, as ferric oxyhydroxides are formed through intermediated products, like green rusts consisting of ferrous and ferric ions. ${ }^{2)}$ The formation or precipitation of ferric oxyhydroxides affects the $\mathrm{pH}$ value, as given in Eq. (3). Actually, the $\mathrm{pH}$ value decreases in the case of pure iron that is reacted for approximately $10 \mathrm{~h}$, as shown in Fig. 9, when the amount of $\mathrm{FeOOH}$ particles increases, as shown in Fig. 8. Since these reactions occur heterogeneously in the solution in a complicated manner, further precise analyses of the suspensions should be required to characterize the elementary reactions. Nevertheless, a possible mechanism for interpreting the influence of silicate ions on the reactions and structures of resulting ferric oxyhydroxides may be discussed. In the case of $\mathrm{Fe}-\mathrm{Si}$ alloy, silicate ions may be formed during its dissolution in the aqueous solution, which corresponds to the oxidation of silicon, like the reaction of Eq. (1) in the case of iron, where the emission of electrons are balanced with the consumption of electrons as given in Eq. (2). As a result, the $\mathrm{pH}$ value of the solution in the case of the Fe-Si alloy may be higher than that for the case of pure iron, although further experiments are required to confirm this model.

In relation to the above changes in the $\mathrm{pH}$, the variations in the ORP of the solutions are shown in Fig. 10. It is known that the ORP increases during the formation of ferric oxyhydroxides from ferrous ions, which is closely correlated with the content of oxygen dissolved in the solution. ${ }^{36-40)}$ However, the oxidation of iron and consumption of oxygen take place simultaneously during the reactions, and ferrous ions formed from metallic iron are also oxidized to form ferric oxyhydroxides by the reaction with oxygen in the solution. Fundamentally, the ORP value is determined by the oxidation of iron and consumption of oxygen in the solution, as shown in Eqs. (1), (2), and (3). In this study, the ORP decreases during the reaction; this may 
be attributed to the simultaneous formation of ferrous ions and ferric oxyhydroxides by the consumption of oxygen in the solution. In both solutions of the Fe-Si alloy, the ORP value decreases in the initial stage and is maintained below that of pure iron during the reaction. This results indicates that the oxidation potential in both solutions of Fe-Si alloy is weaker than that in the solutions of pure iron regardless of the kinds of salts. The reason why the ORP value is maintained at lower value in both solutions of the $\mathrm{Fe}-\mathrm{Si}$ alloy can not be explained simply based on the results of ORP variation, because the reactions of Eqs. (1), (2), and (3) occur simultaneously in complicated manners. Nevertheless, the overall results of $\mathrm{pH}$ and ORP, as shown in Figs. 9 and 10 , suggest that the rate of oxidation from $\mathrm{Fe}^{2+}$ to $\mathrm{Fe}^{3+}$ for the formation of ferric oxyhydroxides seems to decrease in the solutions of 2 mass $\% \mathrm{Na}_{2} \mathrm{SO}_{4}$ and $\mathrm{NaCl}$ in the $\mathrm{Fe}-\mathrm{Si}$ alloy. Therefore, the variations in the $\mathrm{pH}$ and ORP indicate that the formation rate of $\gamma-\mathrm{FeOOH}$ particles is reduced in the solutions by the addition of silicon; this may be consistent with the results of the change in the amount of $\gamma$-FeOOH particles, as shown in Fig. 8. Fundamentally, silicate ions are formed by the oxidation of silicon dissolved in the aqueous solution, ${ }^{31,32)}$ and thus it is considered that the inhibition of $\gamma-\mathrm{FeOOH}$ formation is correlated with the presence of silicate ions during the formation of ferric oxyhydroxides in the solution of $\mathrm{Na}_{2} \mathrm{SO}_{4}$ and $\mathrm{NaCl}$.

The contents of iron and silicon in the initial stages were analyzed in order to consider the formation process of $\gamma$ $\mathrm{FeOOH}$ particles from the $\mathrm{Fe}-\mathrm{Si}$ alloy in the solutions of 2 mass $\% \mathrm{Na}_{2} \mathrm{SO}_{4}$ and $\mathrm{NaCl}$. Figures 11(a) and 11(b) show the content ratio of silicon to iron and the dissolved iron content of the supernatant solutions of $\gamma$-Fe- $\mathrm{Si} / \mathrm{Na}_{2} \mathrm{SO}_{4}$ and $\gamma-\mathrm{Fe}-\mathrm{Si} / \mathrm{NaCl}$ as a function of reaction time, respectively. The variation in the content of iron dissolved in the solution up to $10 \mathrm{~h}$ may be due to significant changes in the solubility of ferrous and ferric irons. ${ }^{2)}$ It should be noted that it is
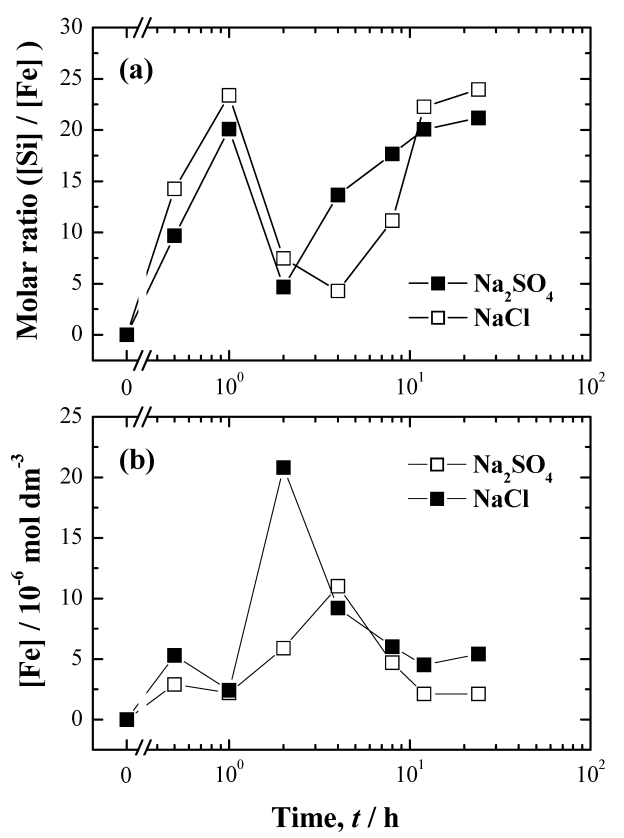

Fig. 11. (a) Content ratio of silicon ( $\mathrm{Si}$ ) to iron (Fe) dissolved in the supernatant solutions of $\gamma-\mathrm{Fe}-\mathrm{Si}_{2} / \mathrm{Na}_{2} \mathrm{SO}_{4}$ and $\gamma$ $\mathrm{Fe}-\mathrm{Si} / \mathrm{NaCl}$ in the initial stages and (b) iron content in the solution as a function of reaction time. difficult to measure the iron content of the supernatant solutions accurately because the ferrous ions are easily oxidized by oxygen in the solution. While the dissolved iron content of the solution is very low, the content of silicon or silicate ions is relatively high despite the fact that the amount of silicon in the Fe-Si alloy is 2 mass\%. Therefore, it is considered that the silicate ions dissolved in the solutions of 2 mass $\% \mathrm{Na}_{2} \mathrm{SO}_{4}$ and $\mathrm{NaCl}$ are involved in the formation of $\gamma$-FeOOH particles. The incorporation of silicate species may lead to the inhibition of $\gamma-\mathrm{FeOOH}$ formation, as shown in Fig. 8. This may affect the atomic-scale structure and morphology of the particles with variations in the $\mathrm{pH}$ and ORP of the solutions.

\section{Concluding Remarks}

Quantitative X-ray structural analysis coupled with RMC simulation, transmission electron microscopy, and infrared spectroscopy was performed to characterize the atomicscale structure and morphology of $\gamma-\mathrm{FeOOH}$ particles. These particles were formed by dipping pure iron and $\mathrm{Fe}-\mathrm{Si}$ alloy in aqueous solutions containing different salts. The solutions were also characterized by the measurements of $\mathrm{pH}$ and ORP and inductively coupled plasma analyses. The main conclusions are summarized as follows:

(1) The pair distribution functions and atomic arrangements determined by the structural analysis revealed that the fundamental $\mathrm{FeO}_{6}$ octahedral units and their linkages were strongly distorted in the $\gamma$-FeOOH particles formed from the Fe-Si alloy. This distortion was due to the incorporation of silicate ions during the formation of $\gamma-\mathrm{FeOOH}$ particles.

(2) Transmission electron micrographs revealed that the morphology of the $\gamma$-FeOOH particles formed from the $\mathrm{Fe}-\mathrm{Si}$ alloy differed from that of the particles formed from pure iron. FT-IR spectra also revealed that new absorption bands were formed in the $\gamma-\mathrm{FeOOH}$ particles produced from the Fe-Si alloy; this suggested the presence of silicate ions in the particles. These results were consistent with those of the atomic-scale structural analysis.

(3) The formation rate of the $\gamma$-FeOOH particles formed from the $\mathrm{Fe}-\mathrm{Si}$ alloy was less than that of the particles formed from pure iron. Correspondingly, the ion content of the solution in which the Fe-Si alloy was dipped differed from that in the case of pure iron. The distortion of the atomic-scale structure of the $\gamma$-FeOOH particles formed from the $\mathrm{Fe}-\mathrm{Si}$ alloy may be related to the formation process in the solution.

\section{Acknowledgement}

The authors would like to express their gratitude to Prof. E. Matsubara and Prof. A. Muramatsu for their valuable discussions. This study was supported by the Grant-in-Aid for Scientific Research Fund of the Japan Society for Promotion of Science (No. 17206075) and the grant of the Iron and Steel Institute of Japan.

\section{REFERENCES}

1) C. Leygraf and T. Graedel: Atmospheric Corrosion, Wiley-Interscience, New York, (2000).

2) R. M. Cornell and U. Schwertmann: The Iron Oxides, Wiley-VCH, 
Weinheim, (2003).

3) H. Okada, Y. Hosoi, K. Yukawa and H. Naito: J. Iron Steel Inst. Jpn., 55 (1969), 355.

4) T. Misawa, M. Yamashita, K. Matsuda, H. Miyuki and H. Nagano: Iron Steel Inst. Jpn., 79 (1993), 69.

5) M. Yamashita, H. Miyuki, K. Matsuda, H. Nagano and T. Misawa: Corros. Sci., 36 (1994), 283.

6) T. Okada, Y. Ishii, T. Mizoguchi, I. Tamura, Y. Kobayashi, Y. Takagi, S. Suzuki, H. Kihira, M. Itoh, A. Usami, K. Tanabe and K. Masuda: Jpn. J. Appl. Phys., 39 (2000), 3382.

7) K. Kamimura, S. Nasu, T. Tazaki, K. Kuzushita and S. Morimoto: Mater. Trans., 43 (2002), 694.

8) S. Nasu, T. Kamimura and T. Tazaki: Hyp. Interact., 139 (2002), 175 .

9) T. Kamimura, S. Nasu, T. Segi, T. Tazaki, S. Morimoto and H. Miyuki: Corros. Sci., 45 (2003), 1863.

10) J. P. Jolivet, C. Chaneac and C. Fiaud: Chem. Commun., (2004), 481

11) T. Sugimoto, K. Sakata and A. Muramatsu: J. Colloid Interface Sci., 159 (1993), 372.

12) K. Shinoda, E. Matsubara, A. Muramatsu and Y. Waseda: Mater. Trans., JIM, 35 (1994), 394.

13) S. Suzuki, M. Saito, M. Kimura, T. Suzuki, H. Kihira and Y. Waseda: ISIJ Int., 43 (2003), 366.

14) S. Suzuki, Y. Takahashi, M. Saito, M. Kusakabe, T. Kamimura, H. Miyuki and Y. Waseda: Corros. Sci., 47 (2005), 1271.

15) S. K. Kwon, S. Suzuki, M. Saito and Y. Waseda: Corros. Sci., 47 (2005), 2543.

16) T. Ishikawa, R. Katoh, A. Yasukawa, K. Kandori, T. Nakayama and F. Yuse: Corros. Sci., 43 (2001), 1727.

17) T. Ishikawa, T. Motoki, R. Katoh, A. Yasukawa, K. Kandori, T. Nakayama and F. Yuse: J. Colloid Interface Sci, 250 (2002), 74.

18) K. Kanie, A. Muramatsu, S. Suzuki and Y. Waseda: Mater. Trans., 45 (2004), 968

19) S. K. Kwon, K. Kimijima, K. Kanie, A. Muramatsu, S. Suzuki, E. Matsubara and Y. Waseda: ISIJ Int., 45 (2005), 77.

20) S. K. Kwon, K. Kimijima, K. Kanie, A. Muramatsu, S. Suzuki, E.
Matsubara and Y. Waseda: Mater. Trans., 46 (2005), 155.

21) S. K. Kwon, S. Suzuki, M. Saito, T. Kamimura, H. Miyuki and Y. Waseda: Mater. Trans., 46 (2005), 155.

22) S. K. Kwon, S. Suzuki, M. Saito, T. Kamimura, H. Miyuki and Y. Waseda: Corros. Sci., 48 (2006), 1571.

23) S. K. Kwon, K. Kimijima, K. Kanie, A. Muramatsu, S. Suzuki and E. Matsubara: High Temp. Mater. Process., 24 (2005), 275.

24) Y. Waseda: Anomalous X-Ray Scattering for Materials Characterization, Springer-Verlag, Heidelberg, (2002).

25) M. Saito, S. Kang and Y. Waseda: Jpn J. Appl. Phys., 38 (1999), 596.

26) M. Saito, S. Kang and Y. Waseda: J. Phys. Sci. Jpn., 68 (1999), 1932.

27) S. Kang, C. Park, M. Saito and Y. Waseda: Mater. Trans., JIM, 40 (1999), 552.

28) G. H. Kelsall and R. A. Williams: J. Electrochem. Soc., 138 (1991), 931.

29) U. Wolff, F. Schneider, K. Mummert and L. Schultz: Corrosion, 56 (2000), 1195.

30) S. Giordana and C. Fiaud: Electrochim. Acta, 47 (2002), 1683.

31) G. H. Kelsall and R. A. Williams: J. Electrochem. Soc., 138 (1991), 941.

32) E. Doelsch, A. Masion, J. Rose, W. E. E. Stone, J. Y. Bottero and P. M. Bertsch: Colloids Surf. A, 217 (2003), 121.

33) D. G. Lewis and V. C. Farmer: Clays Miner, 21 (1986), 93.

34) R. Raman, B. Kuban and A. Razvan: Corros. Sci., 32 (1991), 1295.

35) B. Weckler and H. D. Lutz: Eur. J. Solid State Inorg. Chem., 35 (1998), 531.

36) S. H. Drissi, P. Refait, M. Abdelmoula and J. M. R. Génin: Corros. Sci., 37 (1995), 2025.

37) J. M. R. Génin, A. A. Olowe, P. Refait and L. Simon: Corros. Sci., 38 (1996), 1751.

38) P. Refait and J. M. R. Génin: Corros. Sci., 39 (1997), 539.

39) P. Refait, S. H. Drissi, J. Pytkiewicz and J. M. R. Génin: Corros. Sci., 38 (1997), 1699.

40) P. Refait, M. Abdelmoula and J. M. R. Génin: Corros. Sci., 37 (1995), 1547. 